\title{
Research on the Cooperative Mechanism of Logistics Service in the Innovation of Entity Retail Enterprises
}

\author{
Feng Jianjun \\ ${ }^{1}$ School of Tianjin University of Technology, Tianjin 300384, China \\ a2351477627@qq.com
}

\begin{abstract}
Keywords: Internet thinking; entity retail enterprise; logistics service; collaborative development;
\end{abstract} online to offline

\begin{abstract}
In the context of the new generation of information technology represented by Internet, cloud computing and large data, the consumer demand environment and competitive environment faced by the entity retail industry have undergone tremendous changes. At the same time, physical retail enterprises face greater pressure. In the face of consumers' shopping behavior of fragmented and full channel style, as well as the Internet electricity business more in-depth line layout, the entity retail enterprises need to achieve their own innovation and transformation, change their business model, integration of resources, online to offline collaborative development, optimization enterprise relationship network, improve the quality of logistics services and build a "two - way" value chain. There is an complementary relationship of interdependence, mutual support and between the innovation transformation and the logistics service of the entity retail enterprises. The coordinated development of the two kinds of industry is an inevitable trend, which can better promote the development of the physical retail industry.
\end{abstract}

\section{Introduction}

Background and Significance. Japan, South Korea and other countries have proved that: those enterprise with a strong vitality who can successfully survive the crisis have their own business model and dare to innovate .Retail is the industry that provides the necessary goods and their incidental services to the end consumer . Retail is a bridge between commodity producers and consumers. In the background of continuous development of (mobile) Internet, large data, cloud computing and other technologies, It is a way of thinking on the market, the user, the product, the enterprise value chain and even the entire business ecology to re-examine, and it is the change of consciousness and behavior habits, is the core business model based on customer data.

With the rapid development of science and technology and consumer behavior changes, the business model that the physical store and customer contact directly has been a great impact. The shortcomings of the entity retail business increasingly exposed: profit model is not lasting; the rapid response to consumer demand is not suited to; operating costs are relatively high.[1]

Compared with the traditional physical retail enterprises, the physical retail enterprises after innovative transformation show some different features from the previous: (a) The physical retail enterprises after innovative transformation pay more attention to users. (b) The enterprise after innovative transformation stressed that users should participate in developing product and improving model. (c)The enterprise after innovative transformation should pursue platform-thinking.

Current situation. The rapid development of Internet and mobile Internet and the rapid spread of mobile intelligence bring high-speed development opportunities of e-commerce. Real retail enterprises are facing a serious impact, some enterprises' operating conditions are declining and some physical retail enterprises make ends meet or even risk the result of collapse.

General Office of the State Council issued "Opinions on promoting the innovative transformation of retail entities" It pointed out that the retail entity is an important basis for the circulation of commodities. In view of the existing problems such as extensive mode of development, insufficient supply, low efficiency and so on, promote the retail entity to achieve three changes, by selling goods 
to guide the transformation of production and innovation of the way of life, changing from extensive development to focus on quality and efficiency and from decentralized competition subject to synergy new ecological.[2]

As a result of the above changes in macroeconomic policies and market environment, based on many unfavorable factors real retail enterprises facing suck as property rents, continue high personnel costs, diverted online retailers and the development rate of continuous decline, even some people think that the future is the world of online retail, physical store is valueless, will gradually decline. Now the real retail enterprises are facing these problems: there is no convergence between online and offline goods; Integration issues of online and offline service; online and offline payment system did not get through; the lack of self lifting and distribution function in the store; no online purchases and offline replacement; failed to meet the needs of consumers.

\section{Relevant theoretical basis}

Basic theory of logistics service. In order to meet the needs of economic development, the entire logistics industry has also been rapid development, logistics services also presents a series of features. Comparing the general service characteristics, the characteristics of logistics services are mainly shown in the following aspects (as shown in table 1).

Table 1 comparison of logistics services with general Services

\begin{tabular}{|c|c|c|}
\hline Type & General Services & Logistics services \\
\hline Customer participation & $\begin{array}{l}\text { Customer participation service } \\
\text { process }\end{array}$ & $\begin{array}{l}\text { Customers are highly involved in } \\
\text { the service process }\end{array}$ \\
\hline Production line & no fixed production line & High flexibility \\
\hline $\begin{array}{l}\text { Degree of } \\
\text { informatization }\end{array}$ & $\begin{array}{l}\text { Higher degree of } \\
\text { informatization }\end{array}$ & $\begin{array}{l}\text { The degree of informatization is } \\
\text { very high }\end{array}$ \\
\hline Technical & Technical content is not high & High dependency of technical \\
\hline Degree of integration & $\begin{array}{l}\text { Mostly single or small } \\
\text { individual }\end{array}$ & High service integration \\
\hline Network & $\begin{array}{l}\text { Rarely form a unified network } \\
\text { structure }\end{array}$ & $\begin{array}{l}\text { Form a network system involving } \\
\text { many nodes }\end{array}$ \\
\hline
\end{tabular}

First, customer participation. In the logistics service, not only consumption and production at the same time, and customers customize to their services. Customers at this time is the external actors, but also the internal producers, customers are highly involved in logistics services. Second, flexible. Differences of service quality, determines the fact that services can not be standardized like tangible products, makes the service enterprise have no fixed production line, the same as logistics services. At the same time, logistics services take on an important task to ensure zero inventory of the producers and to meet the needs of those who need in time, which requires logistics enterprises to establish a more flexible logistics system. Third, information technology. In the era of e-commerce, information is the basic requirements of any business. For the logistics enterprises, the degree of information is a key factor to determine the survival of enterprises. Logistics enterprises must form the efficient and convenient information platform of supply chain-based, so that customers can grasp of real-time logistics information, which is logistics services an important part.

Related theory of collaborative development. Synergetics is a kind of knowledge about the various parts of the whole work. The research content is the general rule of the complex system formation structure. These rules include synergies, self-organization principle and servo principle. [3]The details are as follows:

a)Synergistic effect. Synergistic effect is the basic view of synergetics, the result of synergistic effect, and the overall effect produced by the interaction of a large number of subsystems in complex open systems. Each part of the synergy makes the whole show a certain structure and function,it is the synergistic effect of the overall ownership than the various parts of a simple superposition of more powerful features. 
b) Self - organizing principle. Self-organization is a structure or function produced under specific circumstances without external environment. the system will gradually lose stability, When the external environment changes. If the control parameter changes to a wide value, the system will change phase from low-order disorder to high orderly state. This process is spontaneous and does not accept instructions from outside, so it is called self-organization.

c) Servo principle. The servo principle is that the order parameter dominates each part in the critical point of the system phase transition, so that the disordered parts become orderly. Generally speaking, Order parameter is the quantity of longer survival, which is produced by every part in competition and competition.

\section{A successful case of innovation and transformation of real retail enterprises}

Dashang Group, which makes "create a world-renowned company" as the ideal, "unlimited development in every possible way" for the business philosophy, develop physical retail unswervingly, and achieve sales revenue of 200 billion yuan in 2015. Dashang Group has carried out lots of practice such as the transformation and upgrading in real retail, the self-change on business model, the integration of whole channel development in online and offline. These practices provide a sample that is worth learning for the innovation and transformation of China's retail industry.

From the first floor of food mall to create a "eat in Dashang" first store new image, to the electrical store to experience, interactive, intelligent closer to the distance between consumers and goods. At the same, For different situation in different entities shops, Dashang group upgrade through the store function, commodity and store image. Especially in the shop function, in accordance with the principle of a shop a policy, Dashang group enlarge more than 30 cities' old shop according to the standard, requiring all the traditional old shop to take out $25 \%$ to $40 \%$ of the area, to increase the consumption of sticky food and entertainment experience to meet the needs of local consumers. Facing the impact of e-commerce, Dashang Group combine with concept of online business and traditional business based on the advantages of physical store cluster, launched a mobile business “Tengu net" in December 2014, so that the entity store to achieve online and offline integration of all channels of development. Tengu network to follow the "same goods with the price, genuine" business principles, made the value of innovation in the cost of operation, user convenience, social scene for a retail store, achieve integration in online and offline perfect. In terms of operating costs, at present, achieve full digital and electronic, for example, cancel the physical membership card, replace it with the user's mobile electronic membership card and replace small paper tickets with electronic tickets, electronic coupons instead of paper coupons; Dashang Group's all department stores and supermarkets to achieve booking from the mention and delivery home, at present it can ensure that half an hour from the mention and the day home, provide virtual shelves and support the purchase, delivery home around the national.

The transformation of the Dashang group promotes its own development better. By analyzing the reasons for the successful transformation of the Dashang group, the article compares the value chain of the entity retail enterprise and the entity retail enterprise after the innovation transformation, as shown in Figure 3.1 below: 


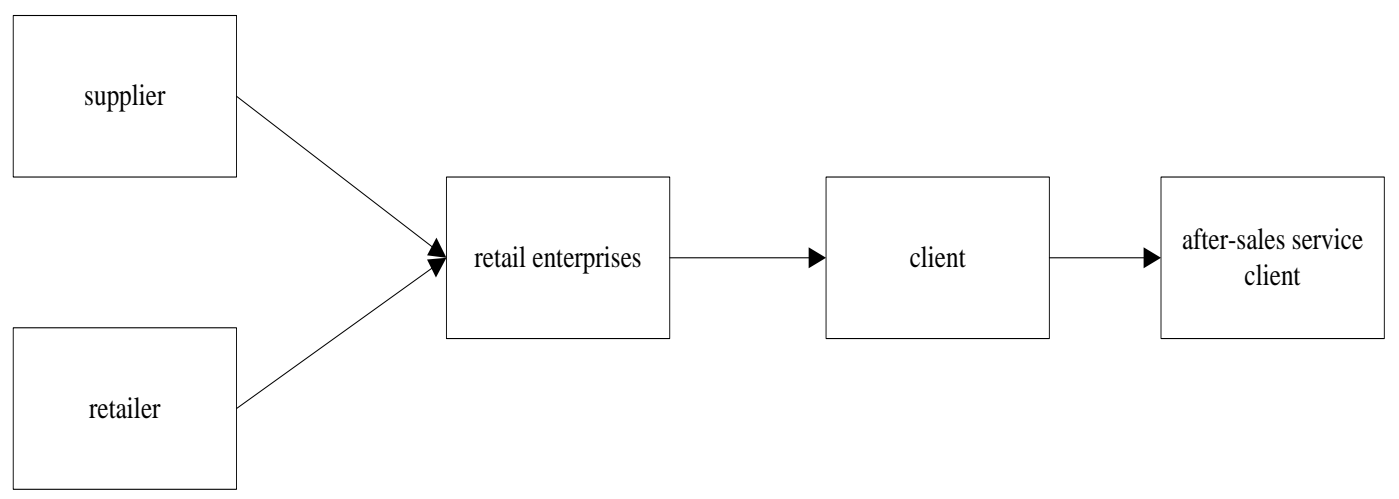

Fig.1 The Traditional Value Chain Retail Enterprises

value-added services, user feedback data utilization, re-purchase, follow-up marketing

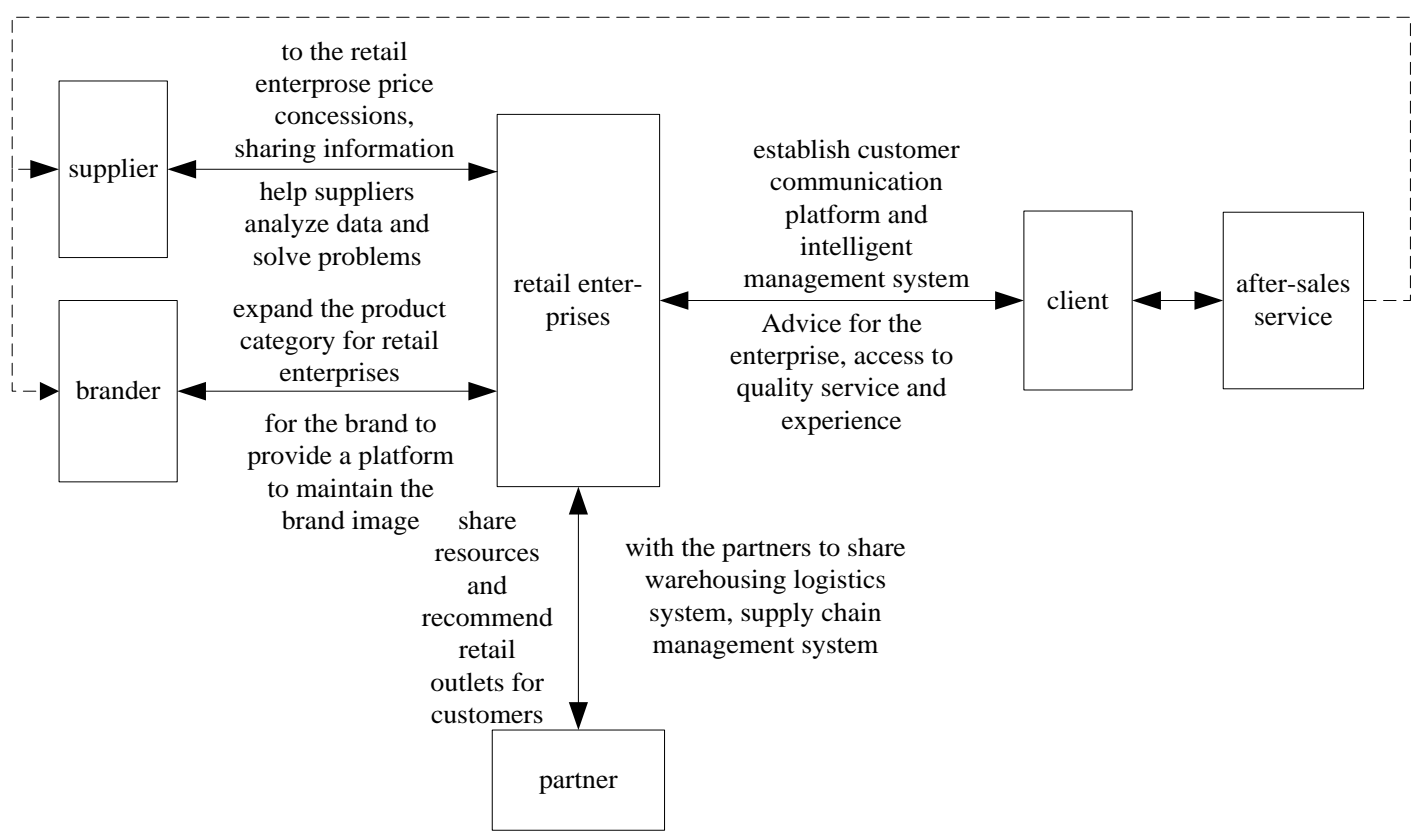

Fig.2 Internet Thinking under the Value Chain Retail Enterprises

\section{Conclusion}

For retail enterprises, because of the different resources, different development goals and other reasons, online and offline integration and maturity are also different, but the innovation model of retail business should follow the online and offline multi-channel integration of the development trend. [4]The perfect combination of online convenience and experience and offline display and service functions, the application of Internet technology and retail core capabilities to fully dock, so as to better meet the needs of consumers, the formation of sustainable business mode. The implementation of online and offline with the same price, close some invalid or inefficient stores, reduce traditional business relatively to improve operational efficiency. Redefine the physical store and power business platform positioning and function. In addition to sales, the store should focus on enhancing the display, experience, service, storage, logistics and other functions to meet the needs of consumers on the experience ; Electronic business platform is equivalent to another form of 24 hours of business entities, focusing on sales, especially the standardization of product sales, focusing on convenience. These two platforms share the same inventory, merchandise, logistics, and services for achieving coordinated development mechanism of the entity retail business after the innovative transformation and logistics services, better promoting its development. 


\section{References}

[1] Song Qian,Wang Neng. Innovation of Business Model of Domestic Retail Enterprises under Internet[J],E-Business Journal,2013,(03):19-20.

[2] Opinions of the General Office of the State Council on Promoting the Innovative Transformation of Entity Retail, issued November 11, 2016.

[3] Liu Dan,Lu Weiwei.Collaborative Development Path of E-commerce Industry and Express Industry in China[J].Technology Economics,2014,(02):45-49.

[4] Guo Xinmei,Zhang Jianli.Analysis of the Major Models and Countermeasures of the Integration of OTO Transactions of China’s Retail Industry[J].Journal of Beijing Technology and Business University(Social Sciences),2014,(05):44-48. 